\title{
Photobiomodulation treatment for head and neck atopic dermatitis resistant to Dupilumab: a case report.
}

\author{
Giulia Tonini ${ }^{1}$, Giulia Davini ${ }^{1}$, Agata Janowska ${ }^{1}$, Michela Iannone ${ }^{2}$, Teresa Oranges ${ }^{1}$, \\ Marco Romanelli ${ }^{1}$, and Valentina Dini ${ }^{1}$ \\ ${ }^{1}$ University of Pisa \\ ${ }^{2}$ University of Pisa
}

April 28, 2020

\begin{abstract}
We report the case of a man affected by atopic dermatitis on dupilumab. During the treatment, the patient showed a worsening of head and neck dermatitis. Blue light irradiation is a safe and efficacy tool for head and neck dermatitis persisting or developed during therapy with dupilumab.
\end{abstract}

\section{Hosted file}

main_text_def_2.doc available at https://authorea.com/users/310441/articles/441304-photobiomodulationtreatment-for-head-and-neck-atopic-dermatitis-resistant-to-dupilumab-a-case-report 


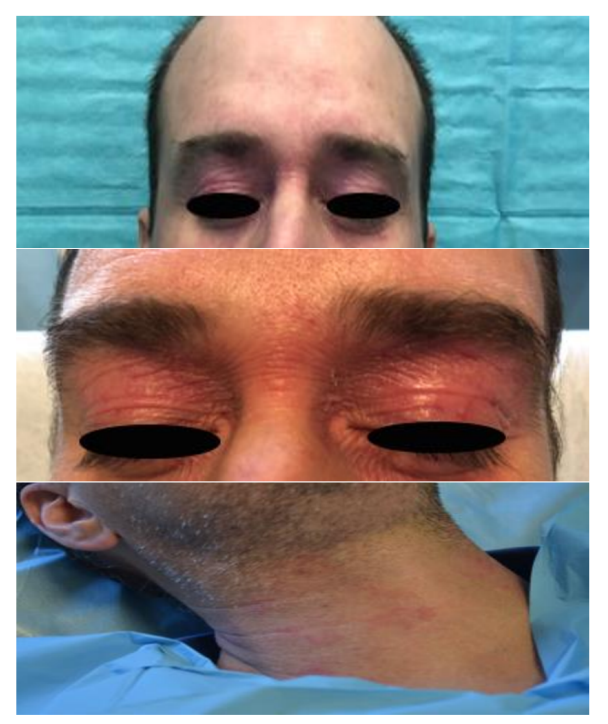




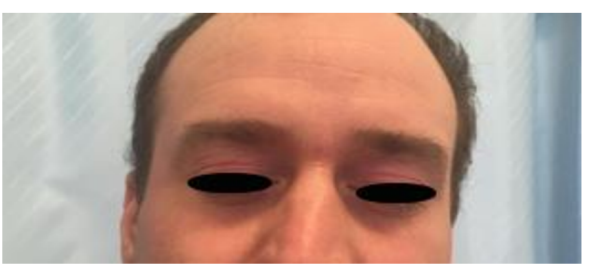




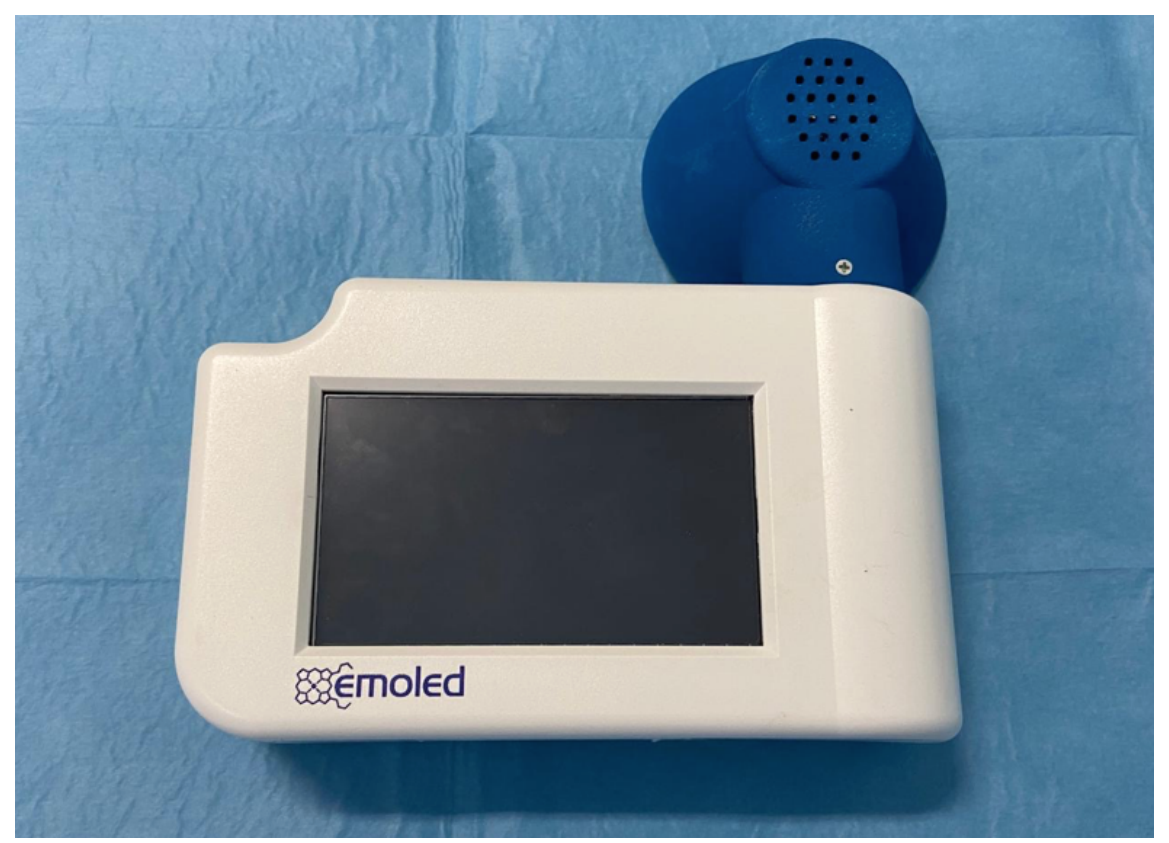

